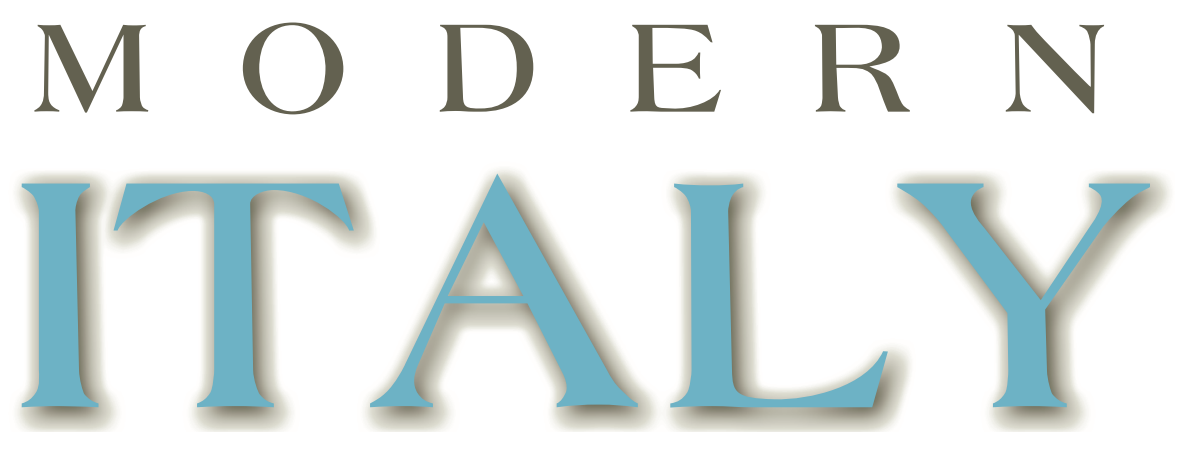

Journal of the Association for the Study of Modern Italy

\title{
Special Issue: The Force of History: Modern Italian Historiography and the Legacy of Christopher Duggan
}




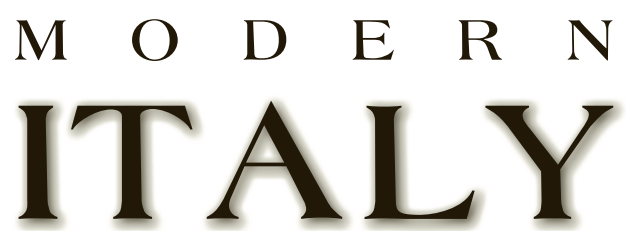

Journal of the Association for the Study of Modern Italy

GENERAL EDITORS

Penelope Morris, University of Glasgow, UK

Mark Seymour, University of Otago, New Zealand

ASSOCIATE EDITORS

Andrea Hajek, Glasgow University, UK

Giacomo Lichtner, Victoria University of Wellington, New Zealand

REVIEWS EDITORS

Fabio Camilletti, University of Warwick, UK

Kate Ferris, University of St Andrews, Scotland

Piero Garofalo, University of New Hampshire, USA

EDITORIAL COMMITTEE

Claudia Baldoli, Newcastle University, UK; Catherine Brice, Université Paris-Est Créteil; Martin Brown, Staffordshire University; Martin Bull, University of Salford, UK; Anna Cento Bull, University of Bath, UK; John Dickie, University College London; Paola Filippucci, University of Cambridge; David Forgacs, New York University, USA; Ruth Glynn, University of Bristol; Stephen Gundle, University of Warwick; Silvana Patriarca, Fordham University, New York, USA; Paolo Pezzino, University of Pisa; John Pollard, University of Cambridge; Perry Willson, University of Dundee

EDITORIAL ADVISORY COMMITTEE

Walter Adamson, Emory University, Atlanta; Percy Allum, University of Naples 'L'Orientale; Richard Bellamy, University College London; Richard Bosworth, University of Western Australia, Oxford; John A. Davis, University of Connecticut; Donatella della Porta, University of Florence; David Ellwood, University of Bologna; Paul Ginsborg, University of Florence; Russell King, University of Sussex; McGregor Knox, London School of Economics and Political Science; Marco Meriggi, University of Naples Federico II; Uffe Østergaard, Aarhus University; Luisa Passerini, University of Turin; Lucy Riall, European University Institute, Florence; Giulio Sapelli, Istituto Feltrinelli, Milan; Frank Snowden, Yale University; Penny Sparke, Kingston University, UK

The Association for the Study of Modern Italy (ASMI)

The Association was founded in November 1982 by Christopher Seton-Watson with the following purposes, as defined in its constitution:

(a) To bring together persons in the United Kingdom who are interested in modern Italy, from whatever discipline or profession.

(b) To organize conferences, meetings, seminars, lectures and exhibitions.

(c) To publish newsletters and other material.

(d) To seek co-operation with appropriate institutions and individuals in Italy and the United Kingdom.

The officers of the Association are: Chair: Lucy Riall; Secretary: Stuart Oglethorpe; Treasurer: Marzia Maccaferri.

ASMI website: http://www.asmi.org.uk

ASMI is registered under the Charities Act 1960: Charity Number 296240.

\section{ASMI Membership}

Membership of ASMI includes a subscription to Modern Italy, together with information mailings to members. Members are also entitled to reductions on fees for conferences and seminars organized or sponsored by ASMI.

Annual Membership subscription rates are $£ 40$ for ordinary members, $£ 20$ for students and the unwaged. To join visit www.asmi.org.uk/ membership.

Christopher Seton-Watson Memorial Prize

A prize of Euro 500 is awarded to the best article published in the journal each calendar year. For details see the ASMI website.

Editorial correspondence should be addressed to Modern Italy, c/o Administrative Hub, School of Modern Languages and Cultures, Hetherington Building, University of Glasgow, Glasgow G12 8RS, UK. Email: modern.italy.journal@glasgow.ac.uk

\section{Aims \& Scope}

Founded in 1995 by the Association for the Study of Modern Italy, the journal's focus is the history, politics, society, economy and culture of Italy, Italian affairs and the Italian peoples from the eighteenth to the twenty-first century.

Modern Italy publishes:

- Fully refereed research articles at the cutting edge of the discipline

- A Regular 'Contexts and Debates' section featuring current controversies in Italian studies and commentaries

on contemporary and historical themes

- Review articles and a comprehensive book reviews section covering the latest Italian and English publications in

Italian studies

- Conference reports and exhibition reviews

- Regular special theme issues

\section{Peer review}

All research articles published in this journal have undergone rigorous peer review, based on initial editor screening and anonymized refereeing by a minimum of two international referees. 


\section{Modern Italy}

VOLUME 22 NUMBER 4 NOVEMBER 2017

\section{PREFACE}

The Force of History: modern Italian historiography and the legacy of

Christopher Duggan

Stephen Gundle

ARTICLES

William Stillman: championing Crispi in late Victorian Britain

David Laven

Christopher Duggan, the mafia and Fascism

Vittorio Coco

Beyond the wall: street art in the fight against the Camorra

Luca Palermo

The Fascist anti-mafia operation in Campania, 1926-1927

Carolina Castellano

Italian-American conversations on the mafia: Danilo Dolci visits Philadelphia's 1961 Festival of Italy

Samantha Owen

Dictatorship revisited: consensus, coercion, and strategies of survival

Paul Corner

Legacies of Fascism: architecture, heritage and memory in contemporary Italy

Hannah Malone

CONTEXTS AND DEBATES

Round Table. The 'British School' and Italian historiography

Ilaria Favretto, Marco Meriggi, David Laven, Giulia Albanese and John Foot

A bibliography of the works of Christopher Duggan

Stuart Oglethorpe

BOOK REVIEWS

Staging the Fascist War: the Ministry of Popular Culture and Italian Propaganda on the Home Front, 1938-1943, by Luigi Petrella

Simonetta Falasca-Zamponi

Italy, Islam and the Islamic World: Representations and Reflections, from 9/11

to the Arab Uprisings, by Charles Burdett

Lucia Sorbera 